\title{
Formulation, in vitro evaluation and characterization of atorvastatin solid dispersion
}

\author{
Asif Iqbal', Md Shafayat Hossain ${ }^{1,2 *}$, Md Abdullah Shamim ${ }^{1,3}$, Monirul Islam, \\ Md Abu Talha Siddique ${ }^{1}$ \\ ${ }^{1}$ Pharmacy Discipline, Life Science School, Khulna University, Khulna-9208, ${ }^{2}$ Veritas Pharmaceutical Ltd, Gazipur, Dhaka, \\ People's Republic of Bangladesh, ${ }^{3}$ Pharmaceutical Sciences, College of Pharmacy, Western University of Health Sciences, \\ Pomona, California-91766, USA, ${ }^{4}$ Department of Pharmacy, Pabna University of Science and Technology, Pabna, People's \\ Republic of Bangladesh
}

*For correspondence: Email: shafayatbd@gmail.com

Sent for review: 20 December 2018

Revised accepted: 15 May 2020

\begin{abstract}
Purpose: To formulate a polymer-incorporated solid dispersion preparation for enhancing the dissolution and bioavailability of atorvastatin calcium trihydrate (ATV), while maintaining oral compatibility.

Method: Four different methods, i.e., physical mixing (PM), fusion (F), solvent evaporation (SE) and kneading $(K)$, as well as three different excipients i.e. croscarmellose sodium (CCS), microcrystalline cellulose (MCC) and lactose (LAC) were used to formulate various drug-carrier combinations.

Results: In SE method, the rank order of magnitude of drug release was CCS $>L A C>M C C$, while in fusion and kneading methods, the rank order of release was MCC > CCS > LAC and MCC > CCS > LAC, respectively. Drug release of atorvastatin was maximum (103 \%) in FM2 formulation. However, this formulation was non-compatible based on spectroscopic analysis. In contrast, SC2 formulations at 1:2 ratio were compatible in terms of cumulative drug release (99\%), and based on spectroscopic data, thermal analysis and microscopic evaluation.

Conclusion: These results confirm that CCS forms a superior interface with atorvastatin when SE formulation method is used. Thus, solid dispersion is a promising approach for enhancing the oral bioavailability of atorvastatin.
\end{abstract}

Keywords: Atorvastatin, Solid dispersion, Bioavailability, Solvent evaporation

\begin{abstract}
This is an Open Access article that uses a fund-ing model which does not charge readers or their institutions for access and distributed under the terms of the Creative Commons Attribution License (http://creativecommons.org/licenses/by/4.0) and the Budapest Open Access Initiative (http://www.budapestopenaccessinitiative.org/read), which permit unrestricted use, distribution, and reproduction in any medium, provided the original work is properly credited.

Tropical Journal of Pharmaceutical Research is indexed by Science Citation Index (SciSearch), Scopus, International Pharmaceutical Abstract, Chemical Abstracts, Embase, Index Copernicus, EBSCO, African Index Medicus, JournalSeek, Journal Citation Reports/Science Edition, Directory of Open Access Journals (DOAJ), African Journal Online, Bioline International, Open-J-Gate and Pharmacy Abstracts
\end{abstract}

\section{INTRODUCTION}

Atorvastatin calcium, a BCS class-II drug, is has low aqueous solubility $(<1 \mathrm{mg} / \mathrm{mL})$ [1]. The low aqueous solubility results in low dissolution and low bioavailability of atorvastatin calcium. Solubility can be increased in different ways, such as particle size reduction through micronization, use of surfactants, solid dispersion (SD) and pro-drug formation $[2,3]$.

Solid dispersion (SD) is a widely recognized approach for increasing solubility drugs that are poorly soluble in aqueous media [4]. It refers to 
the dispersion of drug molecules into a solid matrix consisting of hydrophobic or hydrophilic carrier or polymer $[5,6]$. The carrier or polymer may be either crystalline or amorphous [7].

When the solid dispersion comes in contact with an aqueous environment, the carrier dissolves and turns the drug molecules into fine particles [8]. Therefore, increased surface area enhances dissolution of drugs [9]. Atorvastatin, also known as atorvastatin calcium [10], is used for lowering human blood cholesterol levels. It has significant intestinal permeability [1]. Studies have shown that the bioavailability and solubility of crystalline atorvastatin can be enhanced by converting the drug into an amorphous state, and by reducing its particle size [11].

In a previous study on SD, it was found that the bioavailability of oxcarbazepine was enhanced using fusion method [12]. Another study developed simvastatin solid dispersion with enhanced bioavailability by preparing solid dispersion using SE method, resulting in higher dissolution of simvastatin [13]. In the current study, various drug-excipient mixtures were formulated at two different ratios, i.e. 1:1 and 1:2 using each of the four methods.

The study was aimed at determination of bioavailability of different formulations of atorvastatin using different methods. Moreover, the dissolution profile, drug content and other parameters of the formulations were compared to find out the best formulation with superior water solubility. Furthermore, the physicochemical properties of all formulations were characterized using Fourier-Transform Infrared Spectroscopy (FT-IR), Differential Scanning Calorimetry (DSC), and Scanning Electron Microscopy (SEM).

\section{EXPERIMENTAL}

\section{Materials}

Atorvastatin calcium trihydrate (ATV) was obtained from DSM India Private Limited, India; polyethylene glycol (PEG 6000) was purchased from Hangzhou Zhongbao Imp \& Exp. Corp Ltd, China. Lactose monohydrate was provided by Molkerei Meggle Wasserburg Gmbh \& Co, Germany. Croscarmellose sodium was obtained from Mingtai Chemical Company Ltd, Taiwan, while microcrystalline cellulose was supplied by JRS Pharma Gmbh \& Co, Germany.

\section{Preparation of standard calibration curve}

Atorvastatin calcium trihydrate $(20 \mathrm{mg})$ was weighed into a $1000 \mathrm{~mL}$ volumetric flask. Then,
$100 \mathrm{~mL}$ of methanol was added, with continuous stirring until complete dissolution of ATV. Thereafter, sufficient amount of distilled water $(900 \mathrm{~mL})$ was added to make up the final volume to $1000 \mathrm{~mL}$. The concentration of ATV in this stock solution was $20 \mu \mathrm{g} / \mathrm{mL}$. Then, serial dilutions of the stock solution were prepared in 10 different test tubes, with each concentration in a final volume of $10 \mathrm{~mL}$. The absorbance of each solution was read at $245 \mathrm{~nm}$ in a UV-VIS spectrophotometer (UV mini 1800, Shimadzu Corporation, Japan) [14]. A standard calibration curve was prepared by plotting absorbance values against $A T V$ concentration.

\section{Formulation methods}

\section{Physical mixing}

Drug and excipients were mixed in a mortar and pestle to get a homogeneous physical mixture. Then, the mixture was sieved through a 40 mesh screen to obtain a particle size of $400 \mu \mathrm{m}$. Finally, each formulation was filled in an air-tight vial and preserved with silica gel at room temperature [15].

\section{Melting or fusion}

In this method, $500 \mathrm{mg}$ of PEG-6000 was used as a dispersion carrier. The carrier (PEG) was melted in a $50 \mathrm{~mL}$ beaker at less than $70{ }^{\circ} \mathrm{C}$, and ATV was incorporated with continuous stirring. Following mixing, the mixture was freeze-dried to avoid phase separation, after which it was triturated with various excipients. Finally, the mixture was collected in an air-tight vial and preserved in an air-tight container with desiccators until used [16].

\section{Solvent evaporation}

An appropriate amount of ATV was taken in a 50 $\mathrm{mL}$ beaker, followed by addition of $5 \mathrm{~mL}$ methanol. After sonication, the mixture was kept for $1 \mathrm{~h}$ at room temperature. The resultant crystals were isolated and triturated with different excipients in a mortar and pestle. Then, the various samples were collected in different prelabeled vials and kept in an air-tight container with silica gel as desiccator, for use in further experiments [17].

\section{Kneading}

Excipients and ATV were triturated in a glass mortar with methanol, and the slurry was kneaded for $45 \mathrm{~min}$. Then, the mixture was dried for another $45 \mathrm{~min}$ at $50{ }^{\circ} \mathrm{C}$, followed by pulverization. 
lqbal et al

Table 1: Ratio of ATV and three excipients used in the four methods

\begin{tabular}{|c|c|c|c|c|}
\hline $\begin{array}{l}\text { Physical Mixing } \\
\text { (PM) }\end{array}$ & Fusion (F) & $\begin{array}{l}\text { Solvent Evaporation } \\
\text { (SE) }\end{array}$ & Kneading (K) & $\begin{array}{l}\text { Drug: } \\
\text { carrier } \\
\text { ratio }\end{array}$ \\
\hline $\begin{array}{l}\text { Sample 1: prepared } \\
\text { with PM using CCS } \\
\text { (PC1) }\end{array}$ & $\begin{array}{l}\text { Sample 1: prepared } \\
\text { with F using CCS } \\
(\mathrm{FC} 1)\end{array}$ & $\begin{array}{l}\text { Sample 1: prepared } \\
\text { with SE using CCS } \\
(\mathrm{SC} 1)\end{array}$ & $\begin{array}{l}\text { Sample 1: prepared } \\
\text { with K using CCS } \\
(\mathrm{KC} 1)\end{array}$ & $1: 1$ \\
\hline $\begin{array}{l}\text { Sample 2: prepared } \\
\text { with PM using CCS } \\
\text { (PC2) }\end{array}$ & $\begin{array}{l}\text { Sample 2: prepared } \\
\text { with F using CCS } \\
(F C 2)\end{array}$ & $\begin{array}{l}\text { Sample 2: prepared } \\
\text { with SE using CCS } \\
(\mathrm{SC} 2)\end{array}$ & $\begin{array}{l}\text { Sample 2: prepared } \\
\text { with K using CCS } \\
(\mathrm{KC} 2)\end{array}$ & $1: 2$ \\
\hline $\begin{array}{l}\text { Sample 1: prepared } \\
\text { with PM using MCC } \\
\text { (PM1) }\end{array}$ & $\begin{array}{l}\text { Sample 1: prepared } \\
\text { with F using MCC } \\
\text { (FM1) }\end{array}$ & $\begin{array}{l}\text { Sample 1: prepared } \\
\text { with SE using MCC } \\
(\mathrm{SM} 1)\end{array}$ & $\begin{array}{l}\text { Sample 1: prepared } \\
\text { with K using MCC } \\
\text { (KM1) }\end{array}$ & $1: 1$ \\
\hline $\begin{array}{l}\text { Sample 2: prepared } \\
\text { with PM using MCC } \\
\text { (PM2) }\end{array}$ & $\begin{array}{l}\text { Sample 2: prepared } \\
\text { with F using MCC } \\
\text { (FM2) }\end{array}$ & $\begin{array}{l}\text { Sample 2: prepared } \\
\text { with SE using MCC } \\
(\mathrm{SM} 2)\end{array}$ & $\begin{array}{l}\text { Sample 2: prepared } \\
\text { with K using MCC } \\
(\mathrm{KM} 2)\end{array}$ & $1: 2$ \\
\hline $\begin{array}{l}\text { Sample 1: prepared } \\
\text { with PM using LAC } \\
\text { (PL1) }\end{array}$ & $\begin{array}{l}\text { Sample 1: prepared } \\
\text { with F using LAC } \\
\text { (FL1) }\end{array}$ & $\begin{array}{l}\text { Sample 1: prepared } \\
\text { with SE using LAC } \\
(\text { SL1) }\end{array}$ & $\begin{array}{l}\text { Sample 1: prepared } \\
\text { with K using LAC } \\
(\mathrm{KL} 1)\end{array}$ & $1: 1$ \\
\hline $\begin{array}{l}\text { Sample 2: prepared } \\
\text { with PM using LAC } \\
\text { (PL2) }\end{array}$ & $\begin{array}{l}\text { Sample 2: prepared } \\
\text { with F using LAC } \\
\text { (FL2) }\end{array}$ & $\begin{array}{l}\text { Sample 2: prepared } \\
\text { with SE using LAC } \\
\text { (SL2) }\end{array}$ & $\begin{array}{l}\text { Sample 2: prepared } \\
\text { with K using LAC } \\
(\mathrm{KL} 2)\end{array}$ & $1: 2$ \\
\hline
\end{tabular}

The resultant solid dispersion was preserved in a vial with a desiccator, prior to use [18].

\section{Dissolution studies}

In vitro dissolution study was performed using USP dissolution apparatus II (Electro lab, India). Temperature was maintained at $37 \pm 0.2^{\circ} \mathrm{C}$. At 10 min intervals, $5 \mathrm{~mL}$ sample was withdrawn from the medium, filtered and read at $245 \mathrm{~nm}$ in a UV-VIS spectrophotometer (UV mini 1800, Shimadzu Corporation, Japan) [19].

\section{Fourier-transforms infrared spectroscopy (FT-IR)}

Pure ATV and samples were analyzed using a Fourier-transform infrared spectrophotometer (IR Prestige 21, Shimadzu Corporation, Japan). Each sample (1 - $2 \mathrm{mg}$ ) was dispersed in dried potassium bromide (3 - $4 \mathrm{mg}$ ). The mixture was then compressed into a disc and analyzed at 400 $-4000 \mathrm{~cm}^{-1}$ [20].

\section{Differential scanning calorimetry (DSC)}

The DSC analysis was performed using a DSC 60 Shimadzu Analyzer. Pure ATV samples, solid dispersions and physical mixtures were kept in sealed aluminum pans. The crimped aluminum pans were heated from 30 to $400{ }^{\circ} \mathrm{C}$ at a rate of $10^{\circ} \mathrm{C} / \mathrm{min}$. This experiment was conducted over nitrogen gas at a flow rate of $20 \mathrm{~mL} / \mathrm{min}$ [21].

\section{Scanning electron microscopy (SEM)}

The surface morphology and homogeneity of the prepared formulations from different methods were analyzed using a scanning electron microscope (JSM 6100, Jeol, Japan). A small amount of sold dispersion sample was mounted onto a double adhesive carbon-coated tape adhering to an aluminum stub, and then coated with a thin layer of gold-palladium alloy. Then, the samples were subjected to SEM under numerous magnifications [22].

\section{Statistical analysis}

Data from three independent experiments are presented as mean \pm standard deviation (SD). All graphs were drawn using Microsoft excel (version 16) software. Statistical significance was assumed at $p<0.05$.

\section{RESULTS}

\section{In vitro dissolution profiles}

Although the standard calibration curve of atorvastatin calcium was prepared in phosphate buffer, $\mathrm{pH} 6.8$ as a dissolution medium, the curve showed almost uniform linearity (Figure not shown). The absorbance values of the serial dilutions of ATV used for the standard curve were $0.73,0.58,0.43,0.29$, and 0.14 for ATV concentrations of $20,16,12,8$ and $4 \mu \mathrm{g} / \mathrm{mL}$, 
respectively. The regression coefficient was calculated using the following equation: $y=0.36 x$ - $0.004\left(R^{2}=0.999\right)$.

In physical mixing (PM), the release of ATV was $95.5 \%$ after $60 \mathrm{~min}$, while the ratio of ATV to CCS was 1:2, as shown in Figure 1. This formulation showed the highest cumulative percentage release among the three different binary formulations using the three excipients. The cumulative percentage release of ATV after $60 \mathrm{~min}$ was $62 \%$ for the $10 \mathrm{mg}$ dose. The effect of excipients on drug release from the formulation was in the order: PC2 > PM2 > PL2 (Figure 1).

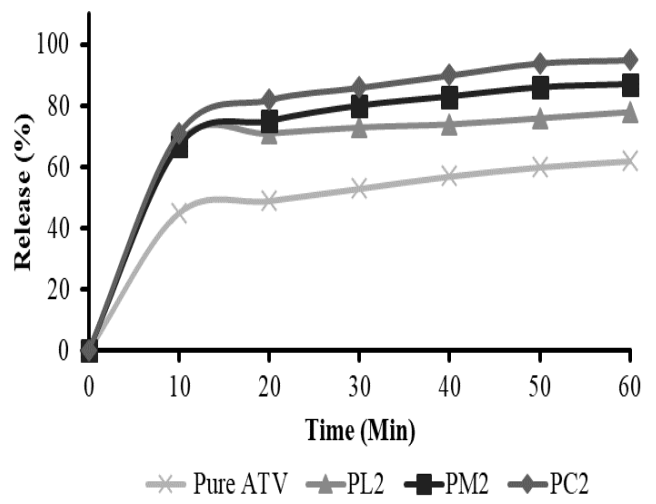

Figure 1: Cumulative release of formulation prepared with PM at drug: carrier ratio of 1:2

In fusion (F) method, FM2 formulation at ATV: MCC ratio of $1: 2$ resulted in the highest cumulative percentage drug release i.e. $103 \%$. The effect of excipients on drug release from the formulation was in the order: FM2 > FC2 > FL2 (Figure 2).

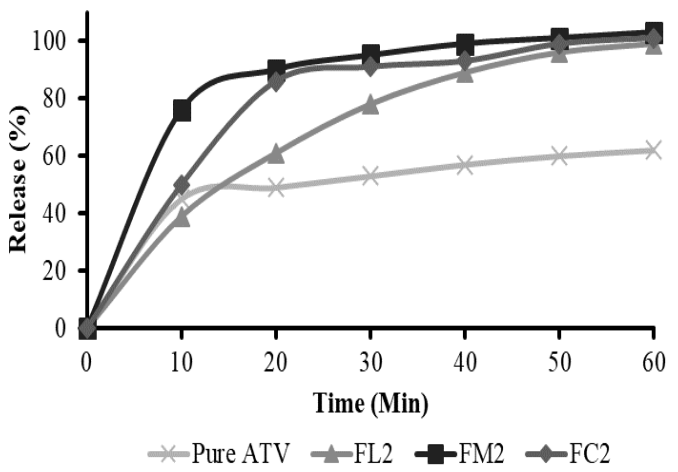

Figure 2: Cumulative release of solid dispersions prepared with fusion method at drug: carrier ratio of $1: 2$

Solvent evaporation (SE) method was less yielding than the fusion (F) method which was found to generate maximum cumulative drug release among all the preparations. The formulation SC2 (ATV:CCS = 1:2) produced the highest cumulative drug release of $99 \%$. Moreover, SC2 resulted in the highest degree of compatibility in the FT-IR and DSC tests among all other preparations. The effect of excipients on drug release from the formulations was in the order: SC2 > SM2 > SL2 (Figure 3).

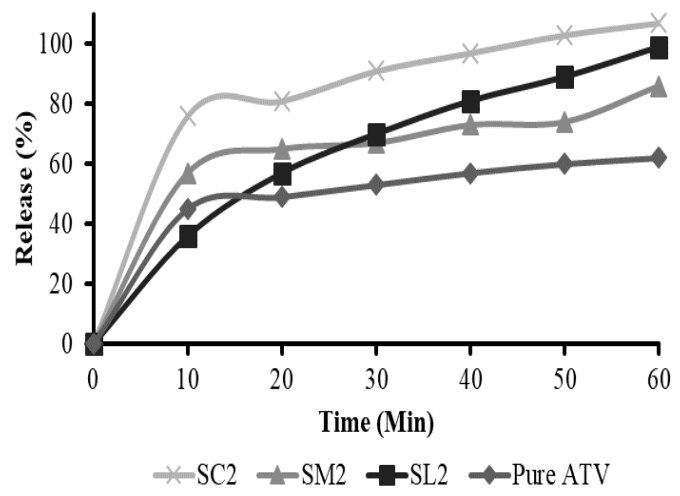

Figure 3: Cumulative drug release of SD prepared with SE method at drug: carrier ratio of $1: 2$

Kneading technique in solid dispersion produced the lowest cumulative drug release among all formulations. The KC2 (ATV:CCS = 1:2) preparation had the highest cumulative release (92 \%) among all the formulations. The effect of excipients on drug release from the formulations was in the order: KC2 > KM2 > KL2 (Figure 4).

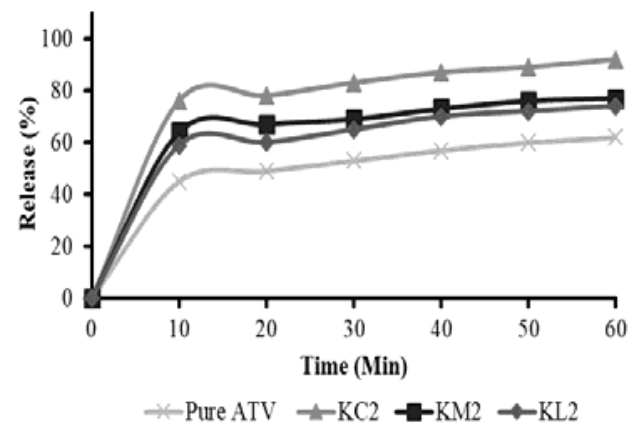

Figure 4: Cumulative release of formulation prepared with kneading method at drug: carrier ratio of 1:2

\section{Characteristics of solid dispersions}

\section{FT-IR spectra}

The FT-IR spectrum of atorvastatin calcium is shown in Figure $5 \mathrm{~A}$. Pure atorvastatin produced characteristic peak at $3400 \mathrm{~cm}^{-1}$ which indicated $\mathrm{N}-\mathrm{H}$ stretching. Moreover, the presence of a peak at $3000 \mathrm{~cm}^{-1}$ denoted the existence of asymmetric $\mathrm{O}-\mathrm{H}$ stretching, while the peak at $2950 \mathrm{~cm}^{-1}$ indicated the presence of symmetric 
$\mathrm{O}-\mathrm{H}$. Likewise, the peak at $1750 \mathrm{~cm}^{-1}$ indicated the presence of carboxyl group in the sample. The spectrum of $\mathrm{SC} 2$ (Figure $5 \mathrm{C}$ ) showed almost all characteristic peaks which apparently indicated a significant drug-carrier interaction in solid dispersion. However, the SM2 (Figure 5 B) and SL2 formulations (Figure 5 D) produced some additional peaks at lower wavelengths (450 - $600 \mathrm{~cm}^{-1}$ ). These additional peaks might have been generated as a result of the presence of $\mathrm{O}$ $\mathrm{H}$ groups in both carriers. Therefore, their dissolutions were comparatively low, as was confirmed from their individual dissolution profiles, as well as DSC and SEM analyses.

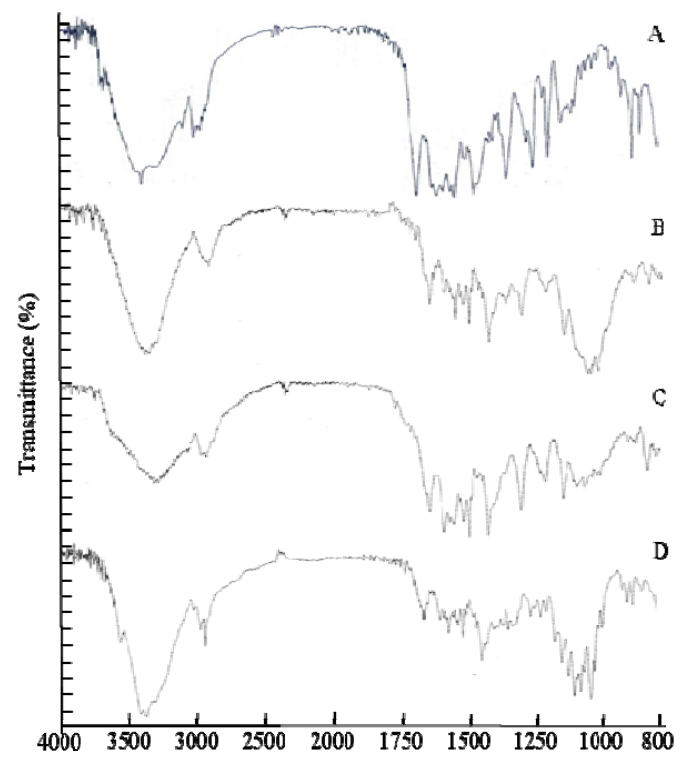

Figure 5: FT-IR spectra of (A) pure ATV; (B) SM2; (C) SC2; and (D) SL2. ATV = atorvastatin, SC2 = ATV: crosscarmellose sodium (1:2); SM2 = ATV: microcrystalline cellulose (1:2); SL2 = ATV: lactose (1:2). All were prepared using solvent evaporation method

\section{Thermal properties}

In this study, three formulations using SE method were considered, and their thermal behaviors were analyzed to confirm the formation of complexes. Pure ATV showed a clear and sharp endothermic peak at $154.55^{\circ} \mathrm{C}$ corresponding to its melting temperature, as well as its crystalline state (Figure $6 \mathrm{~A}$ ). Likewise, the thermogram of SC2 (Figure $6 \mathrm{~B}$ ) showed an endothermic peak at $309.42{ }^{\circ} \mathrm{C}$ which indicated its amorphous state. In contrast, although SM2 formulation produced no sharp peak, a broad endothermic peak at $154.53{ }^{\circ} \mathrm{C}$ (Figure $6 \mathrm{C}$ ) signified the degradation of ATV close to its melting point of $160{ }^{\circ} \mathrm{C}$.

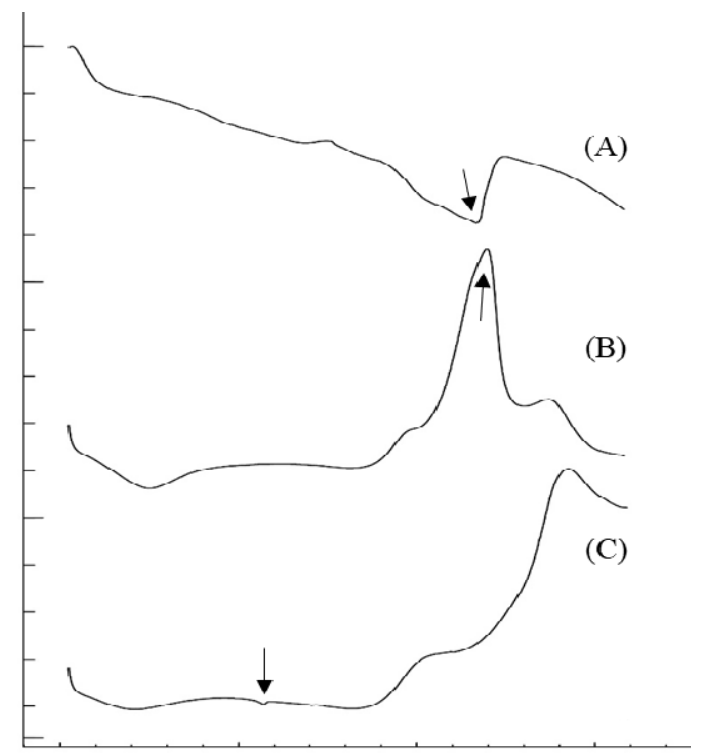

Figure 6: Thermograms of (A) pure ATV; arrow indicates peak temperature $154.55{ }^{\circ} \mathrm{C}$ at $13.55 \mathrm{~min}$, (B) SC2; arrow indicates peak temperature $309.42{ }^{\circ} \mathrm{C}$ at $29.12 \mathrm{~min}$, and (C) SM2; arrow indicates peak temperature $154.53{ }^{\circ} \mathrm{C}$. [ATV $=$ atorvastatin, SECCS $(\mathrm{SC} 2)=\mathrm{SE}($ ATV: C; 1:2); SEMCC (SM2) = SE (ATV: $\mathrm{M} ; \mathrm{1:2}) ; \quad \mathrm{C}=$ croscarmellose sodium, $\mathrm{M}=$ microcrystalline cellulose]

\section{Morphology of pure ATV and solid dispersions}

Investigations of the microscopic structures of pure atorvastatin, solid dispersion of SC2 and SM2 were performed using SEM analysis. Pure ATV (Figure 7 A) appeared as rod-shaped, irregular crystals and agglomerated bundles. These features result in low flow property and difficulties during compression, leading to water solubility. However, the surface morphology of the solid dispersion formulation SC2 (Figure $7 \mathrm{~B}$ ) revealed more amorphous particles than SM2 (Figure $7 \mathrm{C}$ ) and SL2 (Figure $7 \mathrm{D}$ ) formulations. The homogeneous dispersion of particles implied that the drug molecules were fairly distributed within the carrier molecules in the solid dispersion, and that the formulation was in amorphous state.

\section{DISCUSSION}

Carrier-controlled dissolution can be designed on the basis of the dissolution of two-component system - the drug and carrier [23-25]. The drug and carrier dissolve at a rate proportional to their solubility $\left(\mathrm{C}_{\mathrm{s}}\right)$ and diffusion co-efficient $(\mathrm{D})$ of the dissolution medium which result in the release of the drug by increasing the saturation of solubility [26]. 


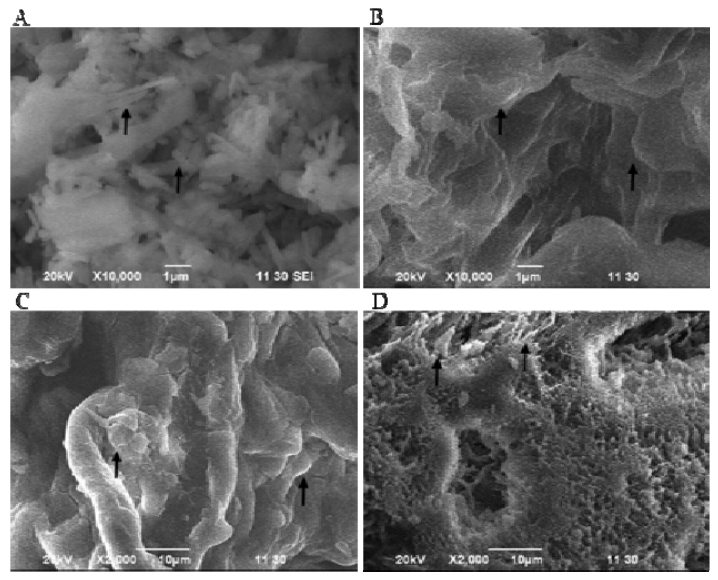

Figure 7: SEM images of (A) pure ATV; arrow indicates granules seems to be in rectangular or rodlike shape, (B) SC2; arrow indicates amorphous state of the granules, (C) SM2; arrow indicates amorphous appearance of the preparation, and (D) SL2, arrow indicates preparation is neither amorphous nor fully crystalline in appearance. [ATV = atorvastatin, SC2 = SE (ATV: $C$ at ratio of 1:2), SM2 = SE (ATV: $M$ at ratio of 1:2); $C=$ croscarmellose sodium, $M=$ microcrystalline cellulose, SL2 = SE (ATV: lactose ratio of $1: 2)$ ]

When the drug is present as a minor component, drug dissolution will be dominated by the dissolution behavior of the carrier. If a drug has a very low solubility relative to the carrier, the dissolution of the drug will be low. In contrast, a more soluble drug produces higher carriercontrolled dissolution rate. Therefore, the dissolution of drugs is significantly influenced by carriers [27]. Several studies have been published on solid dispersion, and each of these studies revealed new results. In solid dispersion, water-soluble drug-carrier complexes occur in special patterns. These patterns change the crystalline and polymorphic natures of certain drugs [28].

The use of microcrystalline cellulose in solvent evaporation method resulted in the highest cumulative drug release (103\%) in FM2 formulation. The use of croscarmellose sodium (SC2 formulation) produced the best cumulative drug release (almost $99 \%$ ). Furthermore, lactose produced the least cumulative drug release among the formulations presented in this study. It was observed that CCS increased drug dissolution due to its swelling and wicking abilities. These properties facilitate the simultaneous use of CCS intra- or extragranularly as a disintegrant. Furthermore, CCS, a comparatively porous excipient, enhanced the disintegration of the dosage form due to its capillary action. In addition, the enhanced dissolution of solid dispersions can be attributed to the formation of hydrogen bonds between the water molecules and the polar groups of atorvastatin, e.g. $\mathrm{C}=\mathrm{O}$ [30].

In this study, the formulations were characterized with FT-IR spectra [15]. Although the FC2 formulation produced the highest cumulative drug release, its spectroscopic characterization was less prominent than that of SC2 formulation, when compared to pure atorvastatin. In addition, the SC2 formulation showed peaks almost identical to those of pure ATV. This implies retention of functional groups. In contrast, the other formulations had peaks different from those of pure atorvastatin, which implies degradation of some of the functional groups e.g. fluorophenyl, carboxyl, and amide groups. This phenomenon can be explained either as a way of masking the functional groups, or as a way of altering them. Chemical alteration or masking of functional groups might be due to formation of complex between the drug and carrier. This complex formation happens in melting and kneading methods, while the applied heat evaporates water molecule from PEG-6000 in the fusion method. Furthermore, the FTIR spectrum of the other two preparations using solvent evaporation method showed deviation from the FTIR spectrum of pure atorvastatin, indicating probable changes in chemical groups responsible for therapeutic effects.

The interaction between a drug molecule and a carrier is determined with differential scanning calorimetry [9]. Among all the formulations, SC2 produced an exothermic peak at $309.45^{\circ} \mathrm{C}$, far beyond the melting point of the drug. This might indicate its crystalline state at this point [31]. However, the spectrum of SC2 showed no characteristic peak close to the melting point of the pure drug, unlike SM2 preparation which showed a small visible peak at $154.53{ }^{\circ} \mathrm{C}$. Consequently, SC2 lacked some features in support of an amorphous drug, although there was also no exothermic peak in the characteristic area to suggest that it is crystalline [7]. In other words, it has similarities with characteristic endothermic peak. However, the other two formulations SC2, produced no sharp peaks, but showed broad endothermic peaks. This phenomenon may support the formation of amorphous state, with the drug molecule dispersed into the matrix [32]. Furthermore, the disappearance of characteristic peaks confirm amorphization of the drug molecule [33]. In a nutshell, SM2 had better dissolution and better DSC spectrum than SC2, but its FTIR spectrum failed to show retention of functional groups identical to those of the pure drug, unlike in the spectrum of SC2. 
The scanning electron microscopic evaluation indicate that pure ATV was crystalline and rodshaped. Therefore, SC2 formulation was regular in shape and size, relative to SM2 and SL2 formulations. In addition, reduction in particle size occurred when the crystalline form changed to amorphous state. Therefore, the increased surface area enhanced dissolution.

\section{CONCLUSION}

The findings of this study demonstrate that hydrophilic polymers can be used to enhance the dissolution of ATV by solid dispersion method. Thus, of all the studied methods, solvent evaporation method is the most suitable in terms of cumulative drug release, spectroscopic, thermal and microscopic characteristics. However, further studies are required to confirm the suitability of the polymers used for largescale manufacturing.

\section{DECLARATIONS}

\section{Acknowledgement}

This project was facilitated by Pharmacy Discipline, Khulna University, Bangladesh and Centre for Advanced Research in Science (CARS), Dhaka University. There was no financial support from any organization.

\section{Conflict of interest}

No conflict of interest is associated with this study.

\section{Contributions of authors}

We declare that this work was done by the authors named in this article and all liabilities pertaining to claims relating to the content of this article will be borne by the authors. Asif Iqbal and Shafayat Hossain contributed to design the study. Asif Iqbal and Monirul Islam carried out the experiments. Asif Iqbal, Shafayat Hossain, Abdullah Shamim, and Talha Siddique analyzed the data and prepared the manuscript. Asif Iqbal, Md Shafayat Hossain and Md Abdullah Shamim contributed equally to the work.

\section{Open Access}

This is an Open Access article that uses a funding model which does not charge readers or their institutions for access and distributed under the terms of the Creative Commons Attribution
License (http://creativecommons.org/licenses/by/ 4.0) and the Budapest Open Access Initiative (http://www.budapestopenaccessinitiative.org/rea d), which permit unrestricted use, distribution, and reproduction in any medium, provided the original work is properly credited.

\section{REFERENCES}

1. Verma S, Rawat A, Kaul M, Saini S. Solid dispersion: a strategy for solubility enhancement. Int J Pharm Technol 2011; 3: 1062-1099.

2. Sukanya M, Kishore VS. Design and development of solid dispersions of simvastatin for enhancing the solubility. Am J PharmTech Res 2012; 2(4): 733-740

3. Rautio J, Kumpulainen $H$, Heimbach $T$, Oliyai $R$, Oh $D$, Järvinen T, Savolainen J. Prodrugs: design and clinical applications. Nat rev Drug discov 2008; 7(3): 255-270.

4. Huang Y, Dai W-G. Fundamental aspects of solid dispersion technology for poorly soluble drugs. Acta Pharm Sin B 2014; 4(1): 18-25.

5. Hu L, Gu D, Hu Q, Shi Y, Gao N. Investigation of solid dispersion of atorvastatin calcium in polyethylene glycol 6000 and polyvinylpyrrolidone. Tro J Pharm Res 2014; 13(6): 835-842.

6. Friesen DT, Shanker R, Crew M, Smithey DT, Curatolo WJ, Nightingale JA. Hydroxypropyl methylcellulose acetate succinate-based spray-dried dispersions: an overview. MolPharm 2008; 5(6): 1003-1019.

7. Janssens S, Van den Mooter G. Physical chemistry of solid dispersions. J Pharm Pharmacol 2009; 61(12): 1571-1586.

8. Kadu PJ, Kushare SS, Thacker DD, Gattani SG. Enhancement of oral bioavailability of atorvastatin calcium by self-emulsifying drug delivery systems (SEDDS). Pharm Dev Technol 2011; 16(1): 65-74.

9. Gubbi SR, Jarag R. Formulation and characterization of atorvastatin calcium liquisolid compacts. Asian J Pharm Sci 2010; 5(2): 50-60.

10. Sharma M, Garg R, Gupta G. Formulation and evaluation of solid dispersion of atorvastatin calcium. J Pharm Sci Innov 2013; 2(4): 73-81.

11. Anwar M, Warsi MH, Mallick N, Akhter S, Gahoi S, Jain GK, Talegaonkar S, Ahmad FJ, Khar RK. Enhanced bioavailability of nano-sized chitosan-atorvastatin conjugate after oral administration to rats. Eur J Pharm Sci 2011; 44(3): 241-249.

12. Mohan A, Madhavi M, Jyosthna P. Preparation, in vitro and in vivo characterization of solid dispersions of oxcarbazepine using melting technique. Pharm Innov J 2015; 3(12): 99-103.

13. Sukanya $M$, Kishore VS. Design and development of solid dispersions of simvastatin for enhancing the solubility. Am J PharmTech Res 2012; 2:733-740.

14. Prajapati KP, Bhandari A. Spectroscopic method for estimation of atorvastatin calcium in tablet dosage form. Indo Global J Pharm Sci 2011; 1(4): 294-299. 
15. Jahan R, Islam MS, Tanwir A, Chowdhury JA. In vitro dissolution study of atorvastatin binary solid dispersion. J Adv Pharm Technol Res 2013; 4(1): 18.

16. Shamsuddin MF, Ansari SH, Ali J. Atorvastatin solid dispersion for bioavailability enhancement. J Adv Pharm Technol Res 2016; 7(1): 22-26.

17. Bobe KR, Subrahmanya CR, Suresh S, Gaikwad DT, Patil MD, Khade TS, Gavitre BB, Kulkarni VS, Gaikwad UT. Formulation and evaluation of solid dispersion of atorvatstatin with various carriers. Int $\mathrm{J}$ Compr Pharm 2011; 02(01): 1-6.

18. Ghareeb MM, Abdulrasool AA, Hussein AA, Noordin MI. Kneading technique for preparation of binary solid dispersion of meloxicam with poloxamer 188. Aaps Pharmscitech 2009; 10(4): 1206-1215.

19. Choudhary A, Rana AC, Aggarwal G, Kumar V, Zakir F. Development and characterization of an atorvastatin solid dispersion formulation using skimmed milk for improved oral bioavailability. Acta Pharm Sin B 2012; 2(4): 421-428.

20. Homayouni A, Sadeghi F, Nokhodchi A, Varshosaz J, Garekani HA. Preparation and characterization of celecoxib solid dispersions; comparison of poloxamer188 and PVP-K30 as carriers. Iran J Basic Med Sci 2014; 17(5): 322-331.

21. Maruthapillai A, Palanisamy K, Sunkara M. Preparation and characterization of rilpivirine solid dispersions with the application of enhanced solubility and dissolution rate. Beni-Suef Univ J Basic Appl Sci 2015; 4(1): 71-79.

22. Yang $M$, Wang $P$, Huang $C Y, K u M S$, Liu $H$, Gogos $C$. Solid dispersion of acetaminophen and poly (ethylene oxide) prepared by hot-melt mixing. Int J Pharm 2010; 395(1-2): 53-61.

23. Prabhu S, Ortega M, Ma C. Novel lipid-based formulations enhancing the in vitro dissolution and permeability characteristics of a poorly water-soluble model drug, piroxicam. Int J Pharm 2005; 301(1-2): 209-216.
24. Perissutti $B$, Rubessa $F$, Mariarosa $M$, Voinovich $D$. Formulation design of carbamazepine fast-release tablets prepared by melt granulation technique. Int $\mathrm{J}$ Pharm 2003; 256(1-2): 53-63

25. Mitchell SA, Reynolds TD, Dasbach TP. A compaction process to enhance dissolution of poorly water-soluble drugs using hydroxypropyl methylcellulose. Int J Pharm 2003; 250(1): 3-11.

26. Overhoff KA, Engstrom JD, Chen. B. Novel ultra-rapid freezing particle engineering process for enhancement of dissolution rates of poor water-soluble drugs. Eur $\mathrm{J}$ Pharm Biopharm 2007; 65(1): 57-67.

27. Hattori $Y$, Haruna $Y$, Otsuka M. Dissolution process analysis using model-free Noyes-Whitney integral equation. Colloids Surf B Biointerfaces 2013; 102: 227 231.

28. Narasaiah LV, Reddy KB, Kishore K, Kumar RM, Rao $S P$, Reddy VB. Enhanced dissolution rate of atorvastatin calcium using solid dispersion with PEG 6000 by dropping method. J PharmSci Res 2010; 2(8): 484-491.

29. Nagarsenker MS, Garad SD. Physical characterization and optimisation of dissolution parameters of prochlorperazine maleate coevaporates. Int J Pharm 1998; 160(2): 251-255.

30. Lieberman HA, Lachman L, Schwartz JB. Pharmaceutical dosage forms: Tablets. 2nd edn. New York, USA: Marcel Dekker, Inc; 1990; pp 15-20, 69.

31. Gubbi SR, Jarag R. Formulation and characterization of atorvastatin calcium liquisolid compacts. Asian J Pharm Sci 2010; 5(2): 50-60.

32. Brittain HG. Physical Characterization of Pharmaceutical Solids (Drugs and Pharmaceutical Sciences). 1st edn. CRS Press; 1995

33. Mura P, Faucci MT, Parrini PL. Effects of grinding with microcrystalline cellulose and cyclodextrins on the ketoprofen physicochemical properties. Drug Dev Ind Pharm 2001; 27(2): 119-128. 